\title{
Diskriminering och exkludering. En introduktion
}

\author{
INGRID SAHLIN \& NORA MACHADO
}

\section{En inledande begreppsdiskussion}

Diskriminering och exkludering är mångtydiga begrepp som försöker fånga komplexa sociala företeelser. Inom samhällsforskningen finns det olika definitioner och modeller som fokuserar på olika aspekter av dessa företeelser.

\section{Strukturell eller institutionell diskriminering}

All diskriminering - i vardagligt tal -är inte olaglig. Olaga diskriminering förutsätter uppsåt och att den negativa särbehandling som åsyftas baseras på att den diskriminerade tillhör en specifik kategori, såsom ras, kön, religionstillhörighet och etnicitet. Den får dessutom inte anses vara sakligt grundad. Om en butiksägare eller krögare inte släpper in en person på grund av personlig antipati mot eller negativ information om just den individen är det alltså inte diskriminering i lagens mening. De som exklu- deras från bostadsmarknaden betraktas vanligen inte som diskriminerade, eftersom en vägran att upplåta bostäder till den som saknar betalningsförmåga anses vara sakligt grundad. Däremot kan man fundera på om det inte vore diskriminering i lagens mening om man gör systematiska undantag från en spärregel (exempelvis att trots allt acceptera etniskt svenska hyresgäster men inte invandrare eller inte svarta med betalningsanmärkning).

Men samhällsvetenskapen begränsas inte av juridiska definitioner, som formats av vad som är möjligt att föra i bevis och bestraffa. Strukturell diskriminering saknar per definition personligt ansvariga aktörer, något som för övrigt ibland har använts som argument mot begreppet (Fransson 2006). Direktiven till utredningen om strukturell diskriminering på grund av etnisk eller religiös tillhörighet definierade detta fenomen som

... regler, normer, rutiner, vedertagna förhällningssätt och beteenden $i$ institutioner och andra samhällsstrukturer som utgör hinder 
för etniska eller religiösa minoriteter att uppnå lika rättigheter och möjligheter som majoriteten av befolkningen har. Sädan diskriminering kan vara synlig eller dold och den kan ske avsiktligt eller oavsiktligt. (Dir. 2003:118s. 3-4)

I betänkandet Det blågula glashuset (SOU 2005:56 s. 22 f.) skriver enmansutredaren Paul Lappalainen att han där använder begreppet strukturell diskriminering för det som i USA och Storbritannien kallas "institutional racism".

Men som vi ser det är strukturell diskriminering och institutionell rasism inte samma sak. För det första vill vi poängtera att all diskriminering inte grundas på rasifiering eller för den delen etnicitet. Diskriminering såväl som exkludering drabbar många olika slags minoriteter och kategorier, och ett av syftena med detta temanummer är att frilägga likheter i de mekanismer och legitimeringar som knyts till olika former av och kontexter för dessa fenomen.

För det andra: är institutionell och strukturell diskriminering verkligen samma sak? Vi skulle snarare hävda att båda begreppen behövs, och då reservera det förra för den form av diskriminering som är sanktionerad i regelsystem, lagar och förordningar och där tillgången till resurser avgörs av definitionen av positionen (Burns et al. 2007, SOU 2005:56, Wodak \& van Dijk 2000). Institutionell diskriminering innebär att vissa grupper systematiskt särbehandlas negativt och får sina möjligheter beskurna. Det sker exempelvis när referenser från tidigare hyresvärdar i Sverige är ett villkor för att få bostad, en princip som utesluter såväl nyligen invandrade som långvarigt bostadslösa, eller när bara svenska arbetsoch utbildningsmeriter beaktas vid anställningsbeslut. Just det systematiska och därmed kontinuerliga i sådan diskriminering, liksom dess legitimering, medför att ojämlikheten permanentas och riskerar att naturaliseras.

Strukturell diskriminering, vill vi hävda, är svårare att härleda till specifika regler och villkor eftersom den härrör ur strukturer och relationer som är delvis juridiska, delvis politiska och ekonomiska och samverkan mellan sådana förhållanden. En alternativ beteckning är ekologisk diskriminering, som framhäver karaktären av aggregerad effekt av flera olika mekanismer, såsom samhällets ekonomiska system, organisation, maktstrukturer, konkurrensförhållanden, resursfördelning etc. (Burns et al. 2008). En annan form är »kulturell diskriminering" som baseras på ett vagt, generaliserat system av gemensamma normer, kategoriseringar, stereotyper och vi-ochdomparadigm (ibid.), utan att det explicit hänvisas till kultur. Exempel på detta är diffusa värderingar av vad det innebär att se "snygg" ut (dvs. välvårdad, »ämpligt" klädd och vältränad), vilket också signalerar en lyckad anpassning till gruppens normativa föreställningar och ideal. De som avviker från detta uppfattas mer eller mindre intuitivt som olämpliga (se Agerström et al. i detta nummer).

I artiklarna definieras diskriminering på varierande sätt, alternativt är definitionsproblemen en fråga i sig. Catharina Calleman för i sin artikel en ingående diskussion om hur diskrimineringslagstiftningen skulle kunna tolkas rättsligt i en situation 
där även den diskriminerande parten kan antas befinna sig i en sårbar situation och därmed skyddas av principer om likaberättigande. Gunnhild Vists bidrag är en analys av norska ungdomars vardagliga men reflekterade definitioner av diskriminering och rasism, där hon visar hur begreppens mening vävs in i och relateras till praktiska situationer och erfarenheter och lokala kontexter och skiljer sig åt beroende på om den som talar identifierar sig med dem som utsatts för rasism eller diskriminering, respektive med dem som anklagas för att diskriminera eller vara rasister.

\section{Exkludering}

Exkludering och diskriminering är relaterade men inte identiska begrepp. Det förra är ibland en förutsättning för det senare, såtillvida att det är lättare att identifiera och därmed särbehandla kategorier och individer som symboliskt eller materiellt placerats utanför det normala eller det gemensamma. Men när en organisation med plats bara för vissa funktioner/egenskaper exkluderar dem som inte passar, eller när man gör skillnad mellan medlemmar och övriga (medborgare, anställda, försäkrade etc.) innebär det inte nödvändigtvis diskriminering. De utestängda kan ju istället ha exklusivt tillträde till en annan klubb, nation eller kassa.

Exkludering kan, men måste inte, å andra sidan vara ett resultat av diskriminering. Den diskriminerade exkluderas ofta från en majoritet eller från en grupp med rättigheter, från något som andra får, är berättigade, tillåts göra eller ha eller vara, men exkludering behöver inte vara följden av att någon men inte andra släpps in. Den kan också vara ett resultat av utstötning av en gruppmedlem.

Begreppet exkludering i den bemärkelse vi använt det och som det undersöks i några av artiklarna i detta nummer är inte detsamma som den engelska termen social exclusion. Det senare blev tongivande inom EU på 1990-talet, sedan dess franska motsvarighet introducerats på 1970-talet som ett alternativ till begrepp som fattigdom, hemlöshet och arbetslöshet. Poängen var ursprungligen att markera att de drabbade var föremål för en utestängningsprocess och inte genom sina egenskaper predestinerade till en svår situation. Begreppet betecknade den successiva förlusten av sociala, ekonomiska, institutionella och kulturella band och de symboliska förbindelser som normalt knyter en individ till hennes eller hans samfund (Silver 1995). Det fokuserade på de omständigheterna individer eller grupper lever under, samtidigt som exkluderade individer eller grupper definierades som socialt sårbara, med sämre livsmöjligheter och färre rättigheter eller sämre möjligheter att realisera dessa.

Social exclusion är alltså ett mångfacetterat begrepp som innefattar brist på både sociala rättigheter och materiella resurser, och som kan användas för att belysa hur och varför individer eller grupper misslyckas med att få tillgång till eller ta del av ekonomiska eller sociala resurser. Problemet i det senaste decenniets diskurser är att detta "varför» i allt högre grad kommit att förknippas med bristfälliga eller olämpliga egenskaper och beteenden hos de exkluderade, i stället för hos dem eller det som 
exkluderar, dvs. en övergång från en "stark» till en "svag" version av begreppet (se bl.a. Martin 2004).

En god illustration av betydelseglidningen ger det faktum att dagens dominerande svenska översättning av social exclusion är "utanförskap», ett begrepp som folkpartiet lanserade med avstamp i Mauricio Rojas analyser i Utanförskapets karta (2004). Utanförskap är ett begrepp som saknar varje slags aktörer och subjekt och som betonar det främmande, annorlunda och avvikande. Dess betydelse knyts idag knappast till det som Becker (1973/2006) avsåg med "outsiders", utan till en situation som framstår som permanent, ohjälplig och knuten till bristfälliga egenskaper hos dem som »befinner sig i utanförskap». De som är utanför är sådana som ingen av oss vill vara och nästan förtjänar att ha det dåligt, och de tenderar att konstrueras som en homogen grupp av "andra». När social exclusion förstås i dessa termer riskerar begreppet att reproducera, istället för att motverka ojämlikhet (Koller \& Davidson 2008).

Med detta temanummer har Socialvetenskaplig tidskrift dock velat gå tillbaka till den ursprungliga betydelsen av exkludering, dvs. själva utestängningsprocessen, inte situationen som utestängd. Framför allt artikeln av Ulla-Carin Hedin och SvenAxel Månsson behandlar detta tema, men även artiklarna av Gunnhild Vist, Tobias Hübinette och Carina Tigervall, respektive Viktorija Kalonaityte, Victoria Kawesa och Adiam Tedros, presenterar och analyserar icke-vitas erfarenhet av själva exkluderingen mer än dess eventuella långsiktiga resultat.

\section{Stigmatisering, diskriminering och exkludering}

Ur ett socialpsykologiskt perspektiv är begreppet stigma relevant för en diskussion om exkludering och diskriminering. Den stigmatiserade - som själv bär bördan av en förminskad och skamfilad social identitet konfronteras med svåra val: att anpassa sig till de »normalas» liv utan att utsätta sig själv och andra för skam genom att förvänta sig en jämlik behandling; att begränsa sin värld till andra stigmatiserade individer eller att leva $\mathrm{i}$ en instabil, semipermanent konflikt med omvärlden. Den som ses ned på, anses mindre värd etc. riskerar just därför exkludering och kan också bidra till sin egen exkludering genom att vara fixerad vid sitt stigma och genom rädsla för andras nedvärdering (Goffman 1963/1972). Exkludering av stigmatiserade, liksom stigmat i sig, är i Goffmans förståelse ett resultat av interaktionen mellan den stigmatiserade och dem som stigmatiserar. Men exkludering kan också leda till stigmatisering, eftersom de exkluderade ofta kategoriseras som farliga, ovärdiga eller som »de andra», som inte är som vi (Elias \& Scotson 1999).

Diskursen om "de andra" förändrades i början av 1980-talet, då rasismbegreppet och dess kopplingar till nazismen övergavs för vad som ibland kallas kulturrasism eller kulturalism. Men även den nyare diskursen bygger på biologism, menar Stolcke (1999), i form av en föreställning om att etnocentrism och xenofobi eller främlingsrädsla, liksom viljan att försvara sitt territorium mot invandrare, beskrivs som "naturliga" för människan: "xenofobi är för kulturell 
fundamentalism vad det biomoraliska begreppet ras är för rasism, nämligen den naturalistiska konstant som legitimerar respektive ideologi“ (Stolcke 1999, s. 29). Sådana föreställningar om det nödvändiga, "naturliga» eller självklara i handlingar och förhållanden som leder till orättvisa, ojämlikhet och kränkningar bidrar starkt till legitimeringar av såväl exkludering som diskriminering, och samtidigt till att stigmarelationer naturaliseras.

Samtliga artiklar i detta tidskriftsnummer behandlar exkludering och diskriminering ganska konkret och ofta i vardagliga sammanhang, som dock implicit eller explicit länkas till övergripande mönster och utfall. Vardagsrasism är ett begrepp som flera författare använder, och som i den här skisserade begreppsramen kan beskrivas som en kontextualiserad diskriminering och/eller exkludering på mikronivå, där dock olika handlingar tillsammans utgör ett mönster (Essed 1991). Blickar, repliker och hur t.ex. en dagisgrupp organiseras eller skolelever grupperas på en promenad belyser en omedveten (och kanske inte alls illa menad) kategorisering i svarta och vita eller invandrare och svenskar, vilken likväl innebär att en minoritetsgrupp utsorteras från majoriteten.

\section{Om detta temanummer}

Tidskriftens "call for papers» våren 2007 till ett temanummer om exkludering och diskriminering fick stor respons. Drygt ett fyrtiotal abstracts kom in; bara en bråkdel av dessa finns representerade i detta nummer. Efter det att de flesta abstracts- författarna inkommit med längre synopsis, inbjöds en mindre andel av dem att sända in färdiga artiklar. Varje insänd artikel granskades sedan i en sedvanlig double blind peer review-process av två anonyma bedömare. Vi vill här passa på tillfället att å våra egna och författarnas vägnar tacka dessa referees för omsorgsfulla granskningar och konstruktiva ändringsförslag.

Det slutliga urvalet av artiklar är ett resultat av en kombination av vår strävan efter en relativ bredd vad gäller perspektiv och ämnen och kvalitetsbedömningar (av gästredaktörerna och anonyma referees). Författarna har olika disciplintillhörigheter och bakgrund. Juridik, psykologi, sociologi, nationalekonomi, socialt arbete och s.k. IMER-forskning är representerade, liksom flera olika universitet och forskningsinstitut; ett bidrag kommer från Norge. Artiklarna behandlar olika kontexter där exkludering och diskriminering äger rum: arbetsplatser, skola, familj och hem, och fritidsumgänge.

En gemensam nämnare för de olika bidragen är avsikten att undersöka hur »den andres" olikhet skapas och normaliseras $i$ vardagen och inom existerande sociala institutioner och maktapparater. Författarna undersöker hur olika skiljelinjer dras på basis av hudfärg, sexuell orientering, nationalitet, kön etc. och hur grupper som befinner sig på den andra sidan om gränsen nedvärderas, särbehandlas negativt och tvingas till underordning. Flera artiklar förmedlar hur en dialektik eller interaktion mellan denna underordning och dess legitimering medför att gruppen på andra sidan gränsen laddas negativt, tillskrivs svagheter och ibland också viss mystik (se Said 1978/1995). 


\section{Begreppsdiskussioner}

Flera bidrag fokuserar på svårigheterna i att teoretiskt fånga eller praktiskt åtgärda diskriminering och exkludering. Catharina Calleman analyserar det komplexa förhållandet mellan allmänna principer om likaberättigande, som i partikulära situationer kan stå i strid mot varandra. Mer konkret visar hon hur den gällande och den kommande diskrimineringslagstiftningen, som är giltig på arbetsmarknaden, i vissa situationer kan komma i konflikt med principen om funktionshindrades rätt till ett normalt liv och individers självbestämmanderätt i hemmiljön, som vid funktionshindrades val av personliga assistenter. Att de förra har rätt att påverka vem som klär dem och tvättar dem och finns i deras hem kan ses som ett självklart skydd för deras integritet, men det kan tyckas lika självklart att en arbetssökande har rätt att bedömas efter sin kompetens och inte efter sin hudfärg eller sexuella läggning, och att en arbetstagare har rätt att fredas mot verbala kränkningar och osakliga uppsägningar.

Gunnhild Vists artikel tar upp hur begrepp för negativa praktiker eller förhållningssätt, såsom rasism och diskriminering, tenderar att överlappa varandra. Hennes artikel aktualiserar begreppens värdeladdning och hur denna kan variera över tid och med kulturell kontext. Hon skriver om norska tonåringars resonemang i grupp omkring vad begrepp som rasism förutsätter: handlar det om förhållningssätt och intentioner, om handling eller om effekter? Det är runt de här aspekterna som diskussionen rör sig i hennes fokusgrupper, precis som i den akademiska debatten. Ett intressant empiriskt resultat är skillnaderna mellan fokusgrupperna med hänvisning till om deltagarna identifierar sig som potentiellt anklagade för respektive drabbade av rasism. Vad betyder det att kalla alla invandrare (från icke-nordiska länder) för "svarta»? Vem avgör om det är kränkande att kalla någon »neger«?

\section{Avslöjandets dynamik}

Oavsett hur lagar tolkas förutsätter deras tillämpning ofta att missförhållanden anmäls till myndigheter eller avslöjas för andra. Konstruktionen av både den "dåliga» flickan, utsatt för sexuella övergrepp (Carlsson) och den "illojala» kritikern (Hedin \& Månsson) bygger på en process av distansering och nedvärdering av den som avslöjar. En annan intressant gemensam nämnare för dessa två artiklar är den specifika spänningen mellan gemenskap och utstötning, liksom den enkelriktade process genom vilken exkluderingen tar form.

Ninni Carlssons ämne är könsdisciplinering som riktas mot flickor som utsatts för sexuella övergrepp av närstående män, och förutsättningarna för att de skall kunna berätta om detta. Hennes intervjupersoner beskriver hur de konstruerats som "dåliga" både när de utsattes för övergreppen och när de försökt avslöja dem för andra. Hon visar att risken är stor för utstötning och avvisande i en sådan situation. Personer i omgivningen kan avvisa uppgiften som osann, överdriven och som skadlig för inte bara den utpekade förövaren utan för hela familjen och definiera den som avslöjat 
övergreppen som medskyldig, lögnaktig och klandervärd - som en »dålig» flicka.

Ulla-Carin Hedin och Sven-Axel Månsson har intervjuat personer som avslöjat problem och oegentligheter i offentliga organisationer och deras artikel analyserar det förlopp varigenom organisationen eventuellt tar till sig kritik men ofta ändå utsätter kritikerna personligen för repressalier. Inte sällan avslutas processen med att den som avslöjat missförhållanden exkluderas ur organisationen genom omplacering eller avsked, eller genom att själv säga upp sig. Författarna analyserar villkoren under vilka kritikerprocessen resulterar i exkludering.

Till repressalierna hör att sprida en viss sorts rykten, som bidrar till att få dem som tidigare sympatiserat med personen eller haft samma kritiska åsikter att själva ta avstånd från honom eller henne. Innehållet i dessa rykten - som att kritikern i själva verket ägnar sig åt en privat vendetta som en överdriven reaktion på en personlig oförrätt - är inte helt olikt det som exempelvis försvarsadvokater kan antyda om kvinnor som polisanmält sexuella övergrepp. Processen kan leda till en seger i sak för den som anmält missförhållanden, men priset är alltså ofta att personen själv blir utfrusen ur den gamla gemenskapen.

Liksom den modiga kritikern förvandlas alltså det utsatta offret inte sällan till "skurk" efter avslöjandet, anklagas för att ha onda avsikter och utsätts för olika utstötningsprocesser. I den klassiska berättelsen om hedersmord på unga flickor, som haft otillåtna relationer med pojkvänner, i vad som officiellt kommit att betecknas som "starkt patriarkala familjer" men inofficiellt ofta förknippas med muslimska utomeuro- peiska invandrare, beskrivs samma process av utdefiniering ur gemenskapen. Det mellanliggande ledet här, det som sägs starta bestraffningsprocessen - vare sig den mynnar ut i uppsägning, emotionell utstötning eller rent av mord - är ofta rädslan för att omgivningen skall få veta vad som försiggått och fördöma familjen/organisationen. På så vis kan bestraffningar utverkas i gruppens (organisationens, familjens) namn, vilket ger dem en kvasilegitimitet - och samtidigt ger upphov till ännu en "familjehemlighet» som kan antas binda samman och disciplinera medlemmarna.

I båda artiklarna beskrivs hur den som för utomstående avslöjar problem och illegitim verksamhet på arbetsplatsen eller i familjen riskerar att anklagas för att skada den egna gruppen. Just detta kan göra att även medlemmar som tidigare visat sympati för deras situation och handlingar nu vänder sig emot dem och ser avslöjandet i sig som ett allvarligare brott än det som avslöjats. Med andra ord: strävan att upprätthålla hedern i omgivningens ögon präglar också gemenskapen i svenska hem och arbetsplatser. Att isolera denna problematik till s.k. hederskulturer, dvs. att hävda att dom men inte vi styrs av strävan att upprätthålla omgivningens respekt, har möjligen bidragit till att osynliggöra den i det svenska majoritetssamhället.

De olika exemplen visar alltså på en särskild form av exkludering, där »brottet" består i att inte vara lojal mot den egna gruppen, och där straffet utgörs av en distinkt utstötning av den som avslöjade. Samma process har bevittnats när någon anmäler diskriminering på sin arbetsplats risken tycks vara stor att personen själv just 
därför kommer att beskrivas som gnällig, överkänslig och annorlunda, och att det är just för att hon är sådan - inte för att hon utsatts för diskriminering eller kritiserat arbetsgivaren - som hon så småningom kommer att utdefinieras.

\section{Stereotyper och exkludering}

Jens Agerströms, Rickard Carlssons, Bo Ekehammars och Dan-Olof Rooths bidrag inom social-kognitiv forskning framhäver betydelsen av omedvetna negativa föreställningar och stereotyper i diskrimineringsprocesser. Resultatet av deras experimentella studier är att socialt definierade kategorier som "arabisk muslimsk man" respektive "överviktig" automatiskt associeras med sämre arbetsprestationer. Detta tyder enligt författarna på att forskningspersonerna - studenter och personalrekryterare - bär på implicita stereotyper, dvs. oreflekterade eller omedvetna föreställningar, som kan antas utöva stort inflytande på beslut om anställning. Denna forskning utgör ett viktigt teoretiskt och empiriskt komplement till institutionellt baserade analyser såväl som intervjustudier och attitydundersökningar.

Nedvärdering baserad på stereotyper exemplifieras också av Anna Malmquists och Kerstin Zetterqvist Nelsons studie av hur par som avviker från den heterosexuella normen konstrueras som olämpliga föräldrar inom auktoritativa diskurser. Den diskursiva konstruktionen av kategorin homosexuella föräldrapar definierar dessa som avvikande (dom) och ställer dem i kontrast till kategorin de normala (oss). Artikeln redovisar en diskursanalys av hur ett antal psykologer resonerar i intervjuer kring två relativt nya lagändringar, vilka gett samkönade par rätt att adoptera (vilket Psykologförbundet avstyrkte), respektive lesbiska par möjlighet till assisterad befruktning (som förbundet inte invände emot).

Intressant är hur man i det första fallet framför allt hänvisade till omgivningens negativa attityder mot homosexualitet som en risk för (utlandsadopterade) barn att hamna i ett "dubbelt annorlundaskap", det författarna kallar en "utifråndiskurs", medan samma intervjupersoner när det gällde assisterad befruktning utvecklade en "inifråndiskurs» om att barnen direkt kunde drabbas av ett underskott av män och ett överskott av kvinnor i familjen. Genom analysen visas också hur föräldrapar bestående av två män osynliggörs och hur starkt föreställningen om den biologiska moderns betydelse - och om att det bara kan finnas en mor - är förankrad i professionen.

I Minoo Alinias bidrag betraktas minoritetskulturer och gemenskapsbildningar bland invandrare inte som uttryck for invandrarkulturer utan som produkter av dessas interaktion med majoritetssamhällena. En av dessa gemenskaper, vilken analyseras i artikeln, är den kurdiska diasporan. Här visas hur nedvärderingsprocesser, tillsammans med tillgången till ett specifikt etniskt utrymme inom en multikulturell social modell, bidrar till att kurder i Sverige identifierar sig med och finner en tillhörighet i en kurdisk diaspora. Denna blir en stark politisk mobiliseringspotential. För denna identitet, baserad på exkludering ur den lokala kontexten (Sverige) men inkludering i en global diaspora, är hemlandet en 
samlande faktor som idé och vision, mer än som en faktisk plats att återvända till.

\section{Vardagens rasifiering}

I den dominerande svenska diskussionen om diskriminering av invandrare och minoriteter har "kulturella skillnader" ofta lyfts fram som problemet, medan hudfärg och utseende nedtonats som grund för särbehandling. Flera olika författare analyserar i detta temanummer förekomst av klassisk rasism i den svenska vardagen. I denna vardagsrasism kopplas utseendemässiga särdrag till stereotypa föreställningar om genetiskt och geografiskt ursprung.

Utseende, namn och språk verkar utgöra stereotypiska strukturer, sociala schemata av förväntningar eller fördomar (Cerulo 2002). Även om språket anses vara den "yttersta markören för nationell tillhörighet", är ett svenskklingande namn och framför allt "rätt utseende» av största vikt för att uppfattas som svensk. Tobias Hübinette och Carina Tigervall fokuserar på betydelsen av fenotypiska egenskaper för erfarenheter hos svenskar adopterade från utlandet och deras föräldrar. Etnicitetsbegreppet problematiseras, då också det fungerar som utgångspunkt för rasifiering. I det perspektivet kan etnicitet och ras inte skiljas åt eftersom både rasbestämningar och etniska tillskrivningar, såsom språk och religion, enligt författarna "faller tillbaka på en viss kropp som avläses som en viss ras, sammankopplad med en viss etnicitet".

De som har mörk hudfärg är ofta också invandrare och talar mindre bra svenska än infödda, vilket kan göra det svårt att föra $i$ bevis att man diskriminerats på grundval av just sin hudfärg. Här erbjuder dock Hübinette och Tigervall ett intressant belägg för förekomsten av oförblommerad rasism i olika vardagliga miljöer som knappast brukar betraktas som rasistiska. Personerna som är i fokus för deras studie, barn som adopterats från utlandet, har nämligen ofta en klassmässig, språklig och kulturell bakgrund som är oskiljbar från etniskt svensk medelklass.

Viktorija Kalonaityte, Victoria Kawesa och Adiam Tedros visar på rasifiering $\mathrm{i}$ beskrivningen av "svarta svenskar", dvs. mörkhyade svenskar med afrikanskt ursprung, och hur dessa exotiseras och diskrimineras i vardagssituationer. Genom en analys av ett stort antal intervjuer visar de på en pågående rasifiering, såväl i homogent vita/svenska områden (vilket i praktiken ofta innebär medelklass) som i etniskt mer heterogena områden. Författarna har också analyserat de svarta svenskarnas strategier av motstånd mot trakasserier och negativ särbehandling, och dilemman de ställs inför. Skall man exempelvis skydda barnen mot rasism eller förbereda dem på mobbning och tillmälen? Skall man trotsa och säga ifrån när man blir negativt bemött, sträva efter att agera förebild genom att synliggöra framgångar eller flytta till mindre rasistiska länder?

Vardagsrasism är ett tema även i Gunnhild Vists artikel. I fokusgrupperna diskuterar ungdomarna olika oklara exempel, där de inte vet om en replik, ett tillmäle eller ett agerande skall - eller kan - uppfattas som ett skämt, som ett tecken på närhet, okunskap eller naivitet, eller som en avsiktlig kränkning. I en av fokusgrupperna berät- 
tade en svart flicka att hon en dag suttit med en tom plats bredvid sig på en buss. Trots att bussen var överfull och många stod upp var det ingen som satte sig bredvid henne, och hon visste inte själv varför. Detta är kanske varken diskriminering eller exkludering men likafullt en viktig aspekt av vardagsrasism: ett kollektivt avståndstagande som drabbar systematiskt utan att varken förklaras eller legitimeras och utan att det är möjligt att peka ut någon ansvarig eller skyldig.

\section{Intersektionalitet och ambivalens}

Samverkan mellan flera olika kategoritillhörigheter - intersektionalitet - bidrar ofta till svårigheter att vetenskapligt renodla diskriminering och utdefiniering och till att rättsligt belägga att en individ eller grupp utsätts för negativ särbehandling. De kvinnor som utsatts för sexuella övergrepp och som Ninni Carlsson intervjuat var när övergreppen begicks både barn och kvinnor och som sådana dubbelt underordnade i familjen. De kurder i Sverige som Minoo Alinia skriver om och som söker en hemhörighet i den kurdiska diasporan har erfarit exkludering från svenska gemenskaper på olika sätt. Männen blir ofta föremål för negativa tillskrivningar och kränkningar och misstänks för kriminalitet och för att förtrycka och misshandla kvinnor, medan kvinnorna är mer ambivalenta inför den kurdiska gemenskapen; en kurdisk kvinna talar om ett dubbelt förtryck: "en gång som kvinna och en gång som kurd». Även erfarenheterna hos de svarta svenskar, som Viktorija Kalonaityte, Victoria Kawesa och Adiam Tedros ger röst åt, skiljer sig åt beroende på kön och ålder. Anna Malmquist och Kerstin Zetterkvist Nelson behandlar lagstiftning om möjligheten att få barn för par som är både homosexuella och barnlösa och visar också på hur samkönat föräldraskap behandlas olika beroende på om det är två män eller två kvinnor som vill ha barn. Catharina Callemans artikel sätter problematiken med olika diskrimineringsgrunder på sin spets genom att vända på maktordningen. Här handlar det om funktionshindrade, en grupp som ofta utsätts för diskriminering, men som just i rollen som arbetsgivare för personliga assistenter plötsligt har en överordnad roll.

Författarnas olika bidrag lyfter alltså fram olika ansikten och nyanser av och grunder för exkludering och diskriminering, och de visar på olika betydelser, lokala varianter, vardagsformer och uttryck av dessa fenomen. Hur de bäst skall grupperas när de presenteras har varit svårt att bestämma, eftersom varje artikel relaterar till flera olika aspekter av diskriminering och exkludering, betraktar olika grunder för dessa och inbjuder till flera läsarter. Vi hoppas läsarna av detta temanummer $i$ likhet med oss gästredaktörer skall finna de nio artiklarna stimulerande, intressanta, tankeväckande och relevanta för den socialvetenskapliga diskussionen. 


\section{Referenser}

Becker, Howard S. (1973/2006) Utanför. Avvikandets sociologi. Lund: Arkiv.

Burns Tom R., Machado Nora, Hellgren Zenia \& Brodin Göran (red.) (2008) Makt, kultur och kontroll över invandrares livsvillkor: Multidimensionella perspektiv på strukturell diskriminering i Sverige. Uppsala: Acta Universitatis Upsaliensis.

Clert, Carine (1999) „Evaluating the concept of social exclusion in development discourse". The European Journal of Development Research vol. $11 \mathrm{nr}$ 2, s. 176-199.

Cerulo, Karen (red.) (2002) Culture in Mind: Toward a Sociology of Culture and Cognition. New York/London: Routledge.

Dir. 2003:118 Strukturell diskriminering på grund av etnisk eller religiös tillhörighet. Kommittédirektiv.

Elias, Norbert \& Scotson, John L. (1999) Etablerade och outsiders. Lund: Arkiv.

Fransson, Ola (2006) "Så blev vi alla rasister". Sociologisk forskning vol. $43 \mathrm{nr}$ 3, s. 5-21.

Essed, Philomena (1991) Understanding Everyday Racism. London, Thousand Oaks, New Dehli: SAGE.

Goffman, Erving (1963/1972) Stigma. Den avvikandes roll och identitet. Prisma ePan.

Koller, Veronika \& Davidson, Paul (2008) "Social exclusion as conceptual and grammatical metaphor: a cross-genre study of British policy- making". Discourse \& Society vol. $19 \mathrm{nr} 3$, s. 307-331.

Martin, Sonia (2004) "Reconceptualising Social Exclusion: A Critical Response to the Neoliberal Welfare Reform Agenda and the Underclass Thesis." Australian Journal of Social Issues vol. $39 \mathrm{nr}$ 1, s. 79-94.

Said, Edward W. (1978/1995) Orientalism. Stockholm: Ordfronts förlag.

SOU 2005:56 Det Blågula glashuset - strukturell diskriminering i Sverige. Betänkande av Utredningen om strukturell diskriminering.

Silver, Hillary (1996) "Culture, Politics and National Discourses of the New Urban Poverty". I Enzo Mingione (red.) Urban Poverty and the Underclass. A Reader. Cambridge, MA: Blackwell.

Stolcke, Verena (1999) „New rhetorics of exclusion in Europer. International Social Science Journal vol. $51 \mathrm{nr}$ 159, s. 25-35.

Utanförskapets karta. En kartläggning över utanförskapet i Sverige (2004). Folkpartiet. www. folkpartiet.se/ImageVault/Images/id_3634/ ImageVaultHandler.aspx

Wodak, Ruth \& van Dijk, Teun A. (red.) (2000) Racism at the top: parliamentary discourses on ethnic issues in six European states. Klagenfurt: Drava.

Young, Jock (1999) The Exclusive Society. London etc.: SAGE. 